\title{
La potestad sancionadora de los entes locales y el principio de legalidad (a propósito de la STS de 29 de mayo de 1998) *
}

\author{
M. ${ }^{2}$ Antonia Arias Martínez \\ Profesora Ayudante de Derecho Administrativo \\ Universidad de Santiago de Compostela
}

Sumario: I. INTRODUCCIÓN. II. PRINCIPIO DE LEGALIDAD Y TIPICIDAD DE INFRACCIONES Y SANCIONES ADMINISTRATIVAS CONSAGRADO EN EL TEXTO CONSTITUCIONAL. II.1. El principio de legalidad. II.2. El principio de tipicidad. III. CONTENIDO DE LA STS DICTADA EN CASACIÓN EL 29 DE MAYO DE 1998. IV. ÓRGANOS COMPETENTES PARA EL EJERCICIO DE LA POTESTAD SANCIONADORA EN EL ÁMBITO LOCAL. V. LA COLABORACIÓN LEY-REGLAMENTO EN EL ÁMBITO DE LA POTESTAD SANCIONADORA LOCAL. VI. ANÁLISIS DE LOS MOTIVOS DEL RECURSO QUE DIO LUGAR A LA STS DICTADA EN CASACIÓN EL 29 DE MAYO DE 1998. VII. LA STS DE 29 DE MAYO DE 1998 Y EL REAL DECRETO 1.398/1993, DE 4 DE AGOSTO, POR EL QUE SE APRUEBA EL REGLAMENTO DE PROCEDIMIENTO PARA EL EJERCICIO DE LA POTESTAD SANCIONADORA.

\section{INTRODUCCIÓN}

En el ámbito del Derecho sancionador una de las cuestiones que más divergencias doctrinales ha suscitado a raíz de la reserva formal de ley prevista para la tipificación de conductas y para el establecimiento de las correspondientes sanciones en el artículo 25 de la CE es la relativa a la potestad sancionadora de los entes locales a través de las Ordenanzas.

Para unos, el ejercicio de la potestad sancionadora por los entes locales debe acomodarse de forma estricta a estos principios tal como han sido interpretados por la jurisprudencia constitucional y, posteriormente, recogidos y positivizados en la Ley de Régimen Jurídico de las Administraciones Públicas y del Procedimiento Administrativo Común (en adelante LPC) ' . Para otros, sin embargo, las peculiaridades de las entidades loca-

\footnotetext{
* Este trabajo ha sido realizado en el marco del proyecto PGIDT99XI20201B de la Xunta de Galicia.

1 Entre otros, destacan E. Garcla de ENTERRIA, «La problemática puesta en aplicación de la LRJ-PCA: el caso del Real Decreto 1.398/1993, de 4 de agosto, que aprueba el Reglamento del procedimiento para el ejercicio de la potestad sancionadora. Nulidad radical del Reglamento y desintegración general del nuevo sistema legal», REDA, n. ${ }^{\circ} 80$, 1993, pp. 665 y ss.; T.-R. FERNÁNDEZ
} 
les exigen una modulación en la esfera local de los principios que con carácter general se predican de la potestad sancionadora ${ }^{2}$.

Esta polémica se ha reavivado tras la emanación por el Gobierno del Estado del Real Decreto 1.398/1993, de 4 de agosto, que aprueba el Reglamento del Procedimiento para el ejercicio de la potestad sancionadora. En este Decreto parece querer reconocérsele un nuevo y mayor alcance a la potestad de los entes locales para dictar Odenanzas. De acuerdo con este Reglamento, como veremos con más detenimiento a lo largo de este trabajo, las Ordenanzas locales pueden tipificar infracciones y sanciones por sí solas con total libertad y, aún más, permite que se considere infracción de las Ordenanzas el incumplimiento total o parcial de las obligaciones o prohibiciones establecidas en las mismas, esto es, cualquier infracción genérica del contenido de las Ordenanzas.

La STS de 29 de mayo de 1998 que sirve de apoyo a este trabajo es importante, más que por su contenido, que, como veremos, reitera los pronunciamientos tanto del propio TS como del TC en esta cuestión, por el momento en que fue dictada, esto es, con posterioridad al citado Real Decreto, lo cual podría haber tentado a dicho Tribunal a dar un giro o una nueva orientación a su doctrina y a sus pronunciamientos.

\section{PRINCIPIO DE LEGALIDAD Y TIPICIDAD DE INFRACCIONES Y SANCIONES ADMINISTRATIVAS CONSAGRADO EN EL TEXTO CONSTITUCIONAL}

De todos es sabido que existe un único ius puniendi del Estado que se manifiesta bien a través de la vía judicial penal o a través de la vía administrativa. En este sentido, la Constitución consagra en su artículo 25 junto a la potestad penal de los Tribunales la potestad sancionadora de la Administración Pública cuyo ejercicio somete, como garantía del Estado de Derecho, a unos límites que coinciden, con ciertos matices, con los

\footnotetext{
RodRfGUez, "La potestad reglamentaria de las Corporaciones Locales», en Administración local, dirigido por S. Martinez-Vares Garcia, Madrid, Consejo General del Poder Judicial, 1995, pp. 213 y ss.

${ }^{2}$ En este sentido pueden verse, entre otros, a A. NIETo, Derecho Administrativo Sancionador, Madrid, Tecnos, 1993, pp. 103 y ss.; C. NAVARro Del CACHO, «Consideraciones sobre la constitucionalidad y la legalidad de la potestad reglamentaria de las entidades locales para la regulación de infracciones y sanciones administrativas", RAAP, $\mathrm{n}^{\circ}{ }^{\circ}$, 1994, pp. 167 y ss.; J. GonzÁlez Pérez y F. González NaVARro, Comentarios a la Ley de Régimen Juridico de las Administraciones Públicas y del Procedimiento Administrativo Común (Ley 30/1992 de 26 de noviembre), Madrid, Civitas, 1997, p. 1865.
} 
principios del orden penal. En este sentido, el TC afirma que «los principios inspiradores del orden penal son de aplicación, con ciertos matices, al Derecho administrativo sancionador, dado que ambos son manifestaciones del ordenamiento punitivo del Estado" ${ }^{3}$. Estos principios son los de legalidad, tipicidad, irretroactividad, responsabilidad, proporcionalidad, prescripción y el de non bis in idem. De todos ellos nos interesa detenernos, de acuerdo con el objeto de análisis de este trabajo, en el estudio de dos de ellos, en concreto, el principio de legalidad y el de tipicidad, cuya conexión en este ámbito es tan estrecha que resultan incluso inextricables.

\section{II.1. El principio de legalidad}

La existencia de un poder sancionatorio en manos de la Administración no plantea dudas. Ahora bien, el ejercicio de dicha potestad está sujeta a ciertos límites de entre los que resalta el principio de legalidad. Éste es un principio que, como afirma NIETO, no afecta a la existencia misma de la potestad sancionadora sino a las condiciones de su ejercicio ${ }^{4}$. De acuerdo con la jurisprudencia del TC, el artículo 25 de la Constitución «incorpora la regla nullum crimen nulla poena sine lege, extendiéndola incluso al ordenamiento sancionador administrativo, y comprende una doble garantía. La primera, de orden material y alcance absoluto, tanto por lo que se refiere al ámbito estrictamente penal como al de las sanciones administrativas, refleja la especial trascendencia del principio de seguridad en dichos ámbitos limitativos de la libertad individual y se traduce en la imperiosa exigencia de predeterminación normativa de las conductas ilícitas y de las sanciones correspondientes. La segunda, de carácter formal, se refiere al rango necesario de las normas tipificadoras de aquellas conductas y reguladoras de estas sanciones, por cuanto, como este Tribunal ha señalado reiteradamente, el término «legislación vigente» contenido en dicho artículo 25.1 es expresivo de una reserva de ley en materia sancionadora" ${ }^{5}$. Lo que en definitiva viene a señalar el TC en esta resolución es la exigencia, derivada del término «legislación» del artículo 25 de la Constitución, de que en el ámbito del Derecho administra-

\footnotetext{
${ }^{3}$ STC 19/1981, de 8 de junio, FJ 2.

${ }^{4}$ A. NieTo, op. cit., p. 88.

${ }^{5} \mathrm{FJ} 2{ }^{\circ}$ de la STC $42 / 1987$, de 7 de abril. Esta doctrina constitucional ha sido reiterada en posteriores pronunciamientos del TC (STC 219/1989, de 21 de diciembre, FJ 2. ; STC 61/1990, de 29 de marzo, FJ 7) y recogida por la jurisprudencia del TS (STS de 20 de enero de 1987 -Ar. 203-, 23 de mayo de 1988 - Ar. 4.196 - 5 de junio de 1992 - Ar. 5.370—).
} 
tivo sancionador la totalidad de las infracciones y sanciones se encuentren tipificadas en una ley formal. En este sentido, el TC concluye en la citada Sentencia que el artículo 25 de la Constitución determina «la necesaria cobertura de la potestad sancionadora de la Administración en una norma de rango legal» 6 .

Con una perfecta y breve sistematización de las decisiones del TC, los Profesores GARCIA DE ENTERRIA y T.-R. FERNÁNDEZ exponen las tres razones que de forma decisiva conducen a interpretar que en el artículo 25 de la Constitución se establece una reserva de ley: i) el hecho de que la reserva de ley es algo incuestionable en el caso de las infracciones penales y la equiparación entre éstas y las administrativas es completa en el artículo 25; ii) el carácter de derecho fundamental que tiene la formulación del artículo 25, lo que hace entrar en juego al artículo 53.1 de la Norma Constitucional, según el cual «sólo por ley... podrá regularse el ejercicio de tales derechos», y iii) el hecho de que la ley sancionatoria delimita el ámbito de lo lícito frente a lo ilícito y, por lo tanto, las fronteras de la libertad, algo que no puede quedar deferido a una simple norma reglamentaria ?.

Ahora bien, la propia jurisprudencia constitucional señala de forma reiterada que esta reserva de ley «no puede ser tan estricta en relación con la regulación de las infracciones y sanciones administrativas como por referencia a los tipos y sanciones penales en sentido estricto" (FJ 2. ${ }^{\circ}$, STC 42/1987). Por ello, el TC establece ciertas matizaciones:

i) La primera hace referencia a normas preconstitucionales de carácter sancionador, respecto de las cuales el TC sostiene que «no es posible exigir la reserva de ley de manera retroactiva para anular disposiciones reguladoras de materias y de situaciones respecto de las cuales tal reserva no existía de acuerdo con el Derecho anterior a la Constitución - STC 11/1981, de 8 de abril, FJ 5. - y, más específicamente por lo que se refiere a las disposiciones sancionadoras, que «el principio de legalidad que se traduce en la reserva absoluta de ley no incide en disposiciones o actos nacidos al mundo del Derecho con anterioridad al momento en que la Constitución fue promulgada - STC 15/1981, de 7 de mayo, FJ $7 .^{\circ} \longrightarrow$ (STC 42/1987, FJ 3. ${ }^{\circ}$ ). Así pues, las normas preconstitucionales en mate-

${ }^{6} \mathrm{FJ} 2 .{ }^{\circ}$ de la STC 42/1987, de 7 de abril, en donde reitera su doctrina de la STC 7/1983, de 3 de octubre.

7 E. Garcla de Enterría y T.-R. Fernandez, Curso de Derecho Administrativo, tomo II, 4. ${ }^{a}$ ed., Madrid, Civitas, 1997, pp. 174-175. 
ria sancionadora no han sido derogadas por la Constitución aun cuando no tuviesen el rango preciso.

ii) El segundo matiz se refiere a la posibilidad de que las leyes contengan remisiones a normas reglamentarias. No obstante, el TC precisa que la reserva de ley no excluye «la posibilidad de que las leyes contengan remisiones a normas reglamentarias, pero sí que tales remisiones a normas reglamentarias hagan posible una regulación independiente y no claramente subordinada a la ley, pues esto último supondría degradar la garantía esencial que el principio de reserva de ley entraña, como forma de asegurar que la regulación de los ámbitos de libertad que corresponden a los ciudadanos depende exclusivamente de la voluntad de sus representantes» (STC 42/1987, FJ 2. ${ }^{\circ}$ ).

En consecuencia, añade el TC, «debe reputarse contraria a las mencionadas exigencias constitucionales no sólo la regulación reglamentaria de infracciones y sanciones carente de toda base legal, sino también, en el ámbito de las relaciones de sujeción general, la simple habilitación a la Administración, por norma de rango legal vacía de todo contenido material propio, para la tipificación de los ilícitos administrativos y las correspondientes consecuencias sancionadoras» (STC 42/1987, FJ 2. ${ }^{\circ}$ ).

Esto significa que está totalmente prohibida en el ámbito del Derecho administrativo sancionador la regulación reglamentaria independiente y no subordinada a la ley. Es decir, el reglamento por sí solo no puede definir infracciones y establecer sanciones aplicables. Por el contrario, es perfectamente legítima la colaboración reglamentaria en materia sancionadora. En este sentido, el TC señala claramente que «lo que prohíbe el artículo 25.1 de la Constitución es la remisión al reglamento que haga posible una regulación independiente y no claramente subordinada a la ley, pero no la colaboración reglamentaria en la normativa sancionadora» (STC 61/1990 de 29 de abril, FJ 8. ${ }^{\circ}$ ). Esta jurisprudencia también es recogida por la doctrina del Tribunal Supremo (SSTS de 29 de abril de 1991 (Ar. 3.526) y de 4 de febrero de 1991 (Ar. 2.888).

De acuerdo con esta doctrina jurisprudencial, a partir de la Constitución la tipificación de infracciones y las correspondientes sanciones sólo podrá venir determinada por una ley o por una norma reglamentaria cuyo contenido esté perfectamente delimitado por una norma con rango de ley. Esta ley de remisión ha de contener siempre «los criterios o "elementos esenciales" de la materia regulada, esto es: el núcleo de la totalidad de 
comportamientos considerados ilícitos y el contenido (naturaleza y límites) de los castigos (SUAY)» ${ }^{8}$.

En nuestros días esta jurisprudencia se encuentra positivizada en la LPC. Así, el principio de legalidad aparece recogido en el artículo 127.1, en el que se establece que «la potestad sancionadora de las Administraciones públicas, reconocida por la Constitución, se ejercerá cuando haya sido expresamente atribuida por una norma con rango de ley, con aplicación del procedimiento previsto para su ejercicio y de acuerdo con lo establecido en este Título»; y también en el apartado 1 del artículo 129, en el que se entremezcla dicho principio con el de tipicidad al disponer que «sólo constituyen infracciones administrativas las vulneraciones del Ordenamiento Jurídico previstas como tales infracciones por una ley. Las infracciones administrativas se clasificarán por la ley en leves, graves y muy graves».

La posibilidad de colaboración reglamentaria en la regulación de infracciones y sanciones señalada por la jurisprudencia constitucional se recoge igualmente en el citado texto legal. De acuerdo con el tenor literal del artículo 129.3, «las disposiciones reglamentarias de desarrollo podrán introducir especificaciones o graduaciones al cuadro de las infracciones o sanciones establecidas legalmente que, sin constituir nuevas infracciones o sanciones, ni alterar la naturaleza o límites de las que la ley contempla; contribuyan a la más correcta identificación de las conductas o a la más precisa determinación de las sanciones correspondientes». Esto implica, en definitiva, que si un reglamento tipifica nuevas conductas como infracciones o innova las sanciones correspondientes sin que exista una ley de cobertura, la jurisdicción contencioso-administrativa podrá declarar su nulidad. Asimismo, el acto de aplicación de una disposición nula por ser contraria al dictado del artículo 25 de la Constitución estará igualmente viciado de nulidad ${ }^{9}$.

\section{II.2. El principio de tipicidad}

Al examinar la jurisprudencia constitucional dictada en relación con el artículo 25.1 de la Constitución observábamos que este precepto encierra

\footnotetext{
8 J. M. Trayter Jimenez y V. Aguado I Cudolá, Derecho Administrativo Sancionador: Materiales, Barcelona, Cedecs, 1995, p. 42.

${ }^{9}$ En este sentido puede verse a J. F. Mestre Delgado, «Los principios del procedimiento sancionadorn, en La nueva Ley de Régimen Juridico de las Administraciones Públicas y del Procedimiento Administrativo Común, dirigida por J. Leguina VILla y M. Sánchez Morón, Madrid, Tecnos, 1993, p. 372.
} 
una doble garantía, una de carácter formal, que se refiere al range de la normativa sancionadora (principio de legalidad), y otra de carácter material, relativa a la exigencia de predeterminación normativa de las conductas ilícitas y de las sanciones correspondientes (STC 42/1987, FJ 3. ${ }^{\circ}$; STC $61 / 1990$, FJ $\left.7 .^{\circ}\right)$, con lo que se está haciendo referencia al principio de tipicidad.

La tipicidad ha sido definida por los Profesores García DE ENTERRÍA y T.-R. FERNÁNDEZ como «la descripción legal de una conducta específica a la que se conectará una sanción administrativa» ${ }^{10}$. Con ello se busca garantizar la seguridad jurídica en ámbitos limitativos de la libertad individual. Se pretende que el destinatario de una norma sancionadora conozca claramente qué comportamientos están prohibidos, cuáles no $\mathrm{y}$, también, qué castigos se le van a aplicar.

En consecuencia, afirma el TC que «la exigencia de lex certa afecta, por un lado, a la tipificación de las infracciones, por otro, a la definición $\mathrm{y}$, en su caso, graduación o escala de las sanciones imponibles y, como es lógico, a la correlación necesaria entre actos o conductas ilícitas tipificadas y las sanciones consiguientes a las mismas, de manera que el conjunto de las normas punitivas aplicables permita predecir, con suficiente grado de certeza, el tipo y el grado de sanción determinado del que pueda hacerse merecedor quien cometa una o más infracciones concretas. Éste es, en definitiva, el significado de la garantía material que el artículo 25.1 de la Constitución establece, en atención a los principios de seguridad jurídica y libertad esenciales al Estado de Derecho» (STC 219/1989 de 21 de diciembre, $\mathrm{FJ} 44^{\circ}$ ). Por lo tanto, este principio de tipicidad en el ámbito del Derecho administrativo sancionador exige que el legislador describa con minuciosidad cada uno de los elementos de la conducta ilícita y sus correspondientes sanciones.

Esta doctrina del TC se encuentra asimismo recogida en la LPC, concretamente en el apartado $1 .^{\circ}$, ya transcrito, del artículo 129 , así como en su apartado 2..$^{\circ}$, en el que se establece que «únicamente por la comisión de infracciones administrativas podrán imponerse sanciones que, en todo caso, estarán delimitadas por la ley».

${ }^{10}$ E. García de Enterría y T.-R. Fernández, op. cit., p. 176. 


\section{CONTENIDO DE LA STS DICTADA EN CASACIÓN EL 29 DE MAYO DE 1998}

Esta Sentencia del Tribunal Supremo (Sala 3. ${ }^{\mathrm{a}}$, Sección $7 .^{\circ}$, ponente Fernando Martín González) tiene su causa en el recurso de casación $\mathbf{n}^{\circ}$ 4876/1995, interpuesto por el Ayuntamiento de Madrid contra una Sentencia dictada por la Sala de lo Contencioso-Administrativo (Sección $8 .^{a}$ ) del Tribunal Superior de Justicia sito en dicha Villa. El Tribunal de la Comunidad Autónoma resuelve el recurso contencioso administrativo interpuesto por el sancionado contra el Decreto dictado por el Cuarto Teniente de Alcalde el 3 de noviembre de 1994, por el que se desestimaba un recurso de reposición entablado contra un Decreto previo dictado el 14 de septiembre del citado año. En virtud de este Decreto y en aplicación del artículo 32.15 de las Ordenanzas de Policía Urbana y Gobierno de la Villa de Madrid de 16 de julio de 1948, posteriormente modificada por un Acuerdo del Pleno de 28 de febrero de 1989, se le imponía al particular una sanción de 10.000 pesetas. El citado artículo 32.15 regula y sanciona el consumo en la vía pública, fuera de los lugares autorizados por las Ordenanzas y reglamentos municipales, de cualquier clase de bebidas que contengan alcohol.

El Tribunal Superior de Justicia de Madrid declara en su Sentencia, ahora recurrida en casación, que las resoluciones impugnadas y el precepto en el que se apoyan, esto es, el artículo 32.15 citado, no respetan el principio de legalidad constitucionalmente consagrado en el artículo 25.1 de la Constitución, pues lo vulneran en su vertiente de reserva formal de ley, por lo que declara su nulidad.

Es sabido que cuando una disposición administrativa infringe el principio de legalidad debe ser declarada nula por los Tribunales del orden contencioso-administrativo. Asimismo, la declaración de nulidad del reglamento conlleva la anulación del acto administrativo sancionador que ha sido dictado bajo su tutela.

El artículo 25.1 del Texto Constitucional ha sido el único precepto analizado y aplicado tanto en la decisión del Supremo como en la Sentencia previamente dictada por el Tribunal Superior de Justicia de Madrid. Teniendo en cuenta que este trabajo girará, básicamente, en torno a dicha disposición constitucional, consideramos que no está de más recordar su tenor literal, según el cual: «Nadie puede ser condenado o sancionado por acciones $u$ omisiones que en el momento de producirse no constituyan delito, falta o infracción administrativa, según la legislación vigente en 
aquei momento.) Con apoyo en este precepto constitucional, el Tribunal de Justicia de Madrid estima que la Ordenanza municipal y su acto de aplicación violan el contenido del principio de legalidad, porque la Corporación carece, por una parte, de competencia en la materia que regula, $y$, por otra, de habilitación para regular y sancionar el supuesto recogido en la citada Ordenanza. En base a ello, los motivos del recurso de casación invocados por la representación del Ayuntamiento de Madrid son dos. En primer lugar, la infracción de la ley por indebida aplicación del artículo 25.1 de la Constitución, al considerar el recurrente que la Ordenanza municipal encuentra cobertura o habilitación legal bastante en los artículos 25, 26 y 79 de la Ley 7/1985, de 2 de abril, Reguladora de las Bases de Régimen Local (en adelante LBRL), relativos, respectivamente, a las competencias municipales y a los bienes de las Corporaciones Locales. El segundo de los motivos del recurso alude a la infracción de ley por indebida aplicación del citado artículo constitucional, al entender el recurrente que la Corporación encuentra habilitación para regular y sancionar el supuesto recogido en el artículo 32.15 de la Ordenanza en: i) el principio de autonomía de las entidades locales (arts. 137 y 140 de la Constitución); ii) la facultad que la Ley reconoce a la Corporación de aprobar Ordenanzas y reglamentos; y iii) la cobertura que a la regulación afectada por el Ayuntamiento le presta la Ley Orgánica 1/1992, de 21 de febrero, de Protección de la Seguridad Ciudadana.

En definitiva, el litigio planteado impone, en primer lugar, estudiar con cierto detenimiento la reserva de ley establecida en el artículo 25 de la Constitución, esto es, el análisis del principio de legalidad y tipicidad de infracciones y sanciones administrativas consagrado en el texto constitucional y, en segundo lugar, determinar si el artículo 32.15 de la citada ordenanza municipal dictada por el Ayuntamiento de Madrid tiene una habilitación legal suficiente que garantice su legitimidad.

\section{IV. ÓRGANOS COMPETENTES PARA EL EJERCICIO DE LA POTESTAD SANCIONADORA EN EL ÁMBITO LOCAL}

La LPC en su artículo 2.1.c) considera Administración Pública a las entidades que integran la Administración local», y la LBRL reconoce de forma expresa en su artículo 4.1.f) la potestad sancionadora de los Municipios, Provincias e Islas. El breve repaso previo de los pronunciamientos jurisprudenciales del TC y del TS en la interpretación de los principios de legalidad y tipicidad que el artículo 25.1 de la Constitución exige en el 
ámbito del Derecho administrativo sancionador nos prepara para descender y centrarnos en el análisis de la aplicación - ¿relajada o, por el contrario, total e integral?- de dichos principios en el ejercicio de la potestad sancionadora por los entes locales.

En la entidad municipal el ejercicio de la potestad sancionadora está atribuida, de acuerdo con la LBRL, al Alcalde «salvo en los casos en que tal facultad este atribuida a otros órganos»" ${ }^{11}$. Asimismo, y en consonancia con esta disposición, el artículo 21.3 de la citada Ley permite al Alcalde delegar en otros órganos de la Corporación el ejercicio de dicho poder sancionador.

Con apoyo en estas disposiciones legales, el acto sancionatorio en el que tiene su origen la STS de 29 de mayo de 1989 es dictado, conforme a lo expuesto en sus fundamentos de Derecho, por el Cuarto Teniente de Alcalde de la Villa de Madrid. Estamos, por lo tanto, ante un supuesto claro de ejercicio de la potestad sancionatoria por delegación del órgano directamente competente, esto es, el Alcalde.

El problema que se plantea en relación a esta cuestión es su compatibilidad con el principio de legalidad tal y como se contemplaba en el apartado 2 del artículo 127 de la LPC. De acuerdo con este precepto, «el ejercicio de la potestad sancionadora corresponde a los órganos administrativos que la tengan expresamente atribuida, por disposición de rango legal o reglamentario, sin que pueda delegarse en órgano distinto»" ${ }^{12}$. Según el tenor literal del precepto, la potestad sancionadora sólo podrá ejercerla el órgano que la tenga atribuida, prohibiendo la LPC la delegación del ejercicio de dicha potestad en un órgano distinto del que la tenga expresamente atribuida. No obstante, cabe realizar en torno a este precepto y su aplicación a este caso que ahora analizamos dos tipos de consideraciones que si bien tienen un contenido contradictorio están apoyadas ambas en pronunciamientos jurisprudenciales.

Por un lado, cabe entender, de acuerdo con el tenor literal del artículo 127.2, que en materia sancionadora no operan las normas generales so-

\footnotetext{
11 Tras la modificación de la LBRL por la Ley 11/1999, de 21 de abril, esta disposición se encuentra contenida en la letra $n$ ) del apartado $1 .^{\circ}$ del artículo 21 de la citada norma.

12 Tras la modificación de la LPC por la Ley 4/1999, de 13 de enero, se suprime la parte final del precepto citado, esto es, la señalada en cursiva en el texto, lo cual implica que a partir de esta reforma de la LPC se permite la delegación del ejercicio de la potestad sancionadora en un órgano distinto del que la tiene expresamente atribuida. No obstante, en el momento en que el TS dicta la Sentencia comentada, la norma aplicable es la contenida en el artículo 127.1 conforme a la redacción dada a dicho precepto por la Ley 30/1992.
} 
bre delegación de competencias de los artículos 12 y 13 de la LPC y si se considera que la LBRL y la LPC son normas con idéntico rango y además que esta última es posterior y plenamente aplicable a las Corporaciones Locales, la sanción impuesta por el Cuarto Teniente de Alcalde de Madrid adolece de un vicio de nulidad al ser dictada por un órgano manifiestamente incompetente ${ }^{13}$.

Sin embargo, nosotros nos inclinamos por aquella posición que considera que la prohibición contenida en el artículo 127 no afecta a las delegaciones previstas en las normas que atribuyen la competencia para el ejercicio de la potestad sancionadora ${ }^{14}$, siempre que se efectúen bajo el respeto de los principios generales previstos sobre delegación de competencias en los artículos 12 y 13 de la LPC. Si la propia Ley atribuidora de la competencia permite la delegación, la garantía que el principio de legalidad sanciona quedaría salvada.

Desde este punto de vista, la prohibición establecida en el artículo 127.2 de la LPC no afecta a las previsiones realizadas por la LBRL sobre la posible delegación de la potestad sancionadora por parte del Alcalde en otros órganos de la Corporación. Esto nos permite concluir que la sanción impuesta por el Cuarto Teniente de Alcalde no padece, desde el punto de vista competencial, vicio de nulidad y es, por lo tanto, plenamente legítima si la norma sectorial, autonómica o estatal que atribuye esa competencia sancionadora prevé la posibilidad de delegación de la competencia. Aun en el supuesto de que la norma sectorial no se pronunciase sobre esta cuestión, la delegación también sería válida por la aplicación supletoria en esta materia de la LBRL.

En apoyo de esta tesis reproducimos a continuación un fragmento de una reciente Sentencia del TS en donde se señala que: «esta Sala estima y así lo declara como doctrina legal, que el artículo 127 de la Ley 30/1992 no deroga lo dispuesto en el artículo 21 de la Ley de Régimen Local, y por tanto en los supuestos de infracción de tráfico podrán delegar los Alcaldes sus atribuciones al estar para ello autorizados por la Ley de Bases de Régimen Local, artículo 21, y ello, cual se ha visto, valorando,... que la Ley de Bases

13 Ésta es una doctrina jurisprudencial reiterada. En este sentido pueden verse las Sentencias del Tribunal Superior de Xusticia de Galicia de 24 de julio de 1997, n. $.^{\circ} 952 / 1997$, de 25 de noviembre de $1997, \mathrm{n} .^{\circ} 1.428 / 1997$ y de 15 de enero de 1998, n. $^{\circ} 23 / 1998$.

14 En este sentido, véase a C. CHINCHILla MARín, «Potestad sancionadora de las Administraciones Públicas (arts. 127 a 138)», Administraciones Públicas y Ciudadanos (Estudio sistemático de la Ley 30/1992, de 26 de noviembre, de Régimen Juridico de las Administraciones Públicas y del Procedimiento Administrativo Común), coordinador B. Pendas Garcí, Barcelona, Praxis, 1993, p. 754. 
de Régimen Local tenía ya establecido un régimen propio, en la determinación del régimen sancionador, que era conforme a los principios generales que sobre órganos y competencias ha establecido la Ley 30/1992, artículo 12 , y que en su artículo 21 es el propio legislador el que autoriza la delegación de atribuciones en materia sancionadora a los Alcaldes... Sin olvidar que la distinta configuración y estructura de uno y otro ordenamiento, el de la Administración General con variedad y diversidad de órganos y el de la Administración Local con sólo un órgano unipersonal, justifican, en su caso, un distinto régimen en materia de delegaciones, y que si no se admitiese la delegación de los Alcaldes resultaría ciertamente difícil que puedan cumplir todas sus funciones y ajustar su actuación al principio de eficacia que exige el artículo 103 de la Constitución española» ${ }^{15}$.

\section{LA COLABORACIÓN LEY-REGLAMENTO EN EL ÁMBITO DE LA POTESTAD SANCIONADORA LOCAL}

Partimos en este momento de un postulado incuestionable: los entes locales en su calidad de Administración Pública territorial son titulares de la potestad sancionadora. Ahora bien, este poder será ejercitado por su titular «cuando haya sido expresamente atribuido por una norma con rango de ley» (art. 127.1 LPC). Como ya hemos visto, esto supone la consagración a nivel legislativo del principio de legalidad, es decir, que las sanciones e infracciones se encuentren tipificadas en una rorma con rango de ley. Esto implica, desde un punto de vista negativo, que las Ordenanzas locales, en cuanto norma reglamentaria y, por lo tanto, carentes de rango legal, no scn el cauce hábil o legítimo para tipificar conductas ilícitas ni para establecer las correspondientes sanciones. Sin embargo, sabemos que las Ordenanzas no quedan excluidas del ámbito sancionador de la Administración y que, de acuerdo con la jurisprudencia constitucional arriba citada, cabe la colaboración de normas reglamentarias en la definición del ilícito y de las correspondientes sanciones.

La cobertura legal que exige el principio de legalidad se cumple, en relación con la tipificación de las sanciones, en virtud del artículo 59 del TR, en el que se establece que, salvo previsión legal expresa distinta, la cuantía de las multas por infracción de Ordenanzas no podrá exceder, de 25.000 pesetas en Municipios de más de 500.000 habitantes; de 15.000 pesetas en los de 50.001 a 500.000 ; de 10.000 pesetas en los de 20.001 a 50.000 ; de 5.000 pesetas en los demás Municipios.

${ }^{15}$ STS de 10 de noviembre de 1998 (Ar. 9.465). 
En los Fundamentos de Derecho de la STS de 29 de mayo de 1998 se le impone al sancionado, en aplicación del artículo 32.15 de las Ordenanzas de Policía Urbana y de Gobierno de la Villa de Madrid, una multa que asciende a una cuantía de 10.000 pesetas, lo que significa que desde el punto de vista de la sanción impuesta se respeta el contenido del artículo 59 del TR y, en consecuencia, el principio de legalidad consagrado en el artículo $25 \mathrm{CE}$.

No obstante, el problema que se presenta en esta ocasión es averiguar si existe una ley que, si no agote, al menos, fije algunos de los criterios que sirvan para definir el tipo. En este sentido, hemos de recordar que la potestad reglamentaria de los entes locales se deriva del reconocimiento constitucional de la autonomía para gestionar sus propios intereses (art. $137 \mathrm{CE}$ ) dentro del ámbito de competencias que por ley estatal o autonómica les sean reconocidas (art. 2 y 25.3 de la LBRL). De esta forma, las competencias de los entes locales están determinadas por las leyes sectoriales, siendo éstas «las que nos dan la medida exacta de la competencia $y$, en definitiva, de la potestad sancionadora» ${ }^{16}$.

En este sentido, la Sentencia ahora comentada reitera que «una Ordenanza municipal no puede ser fuente primaria de un Ordenamiento sancionador, ni aun en el ámbito de las relaciones de sujeción especial, y que su oportunidad reguladora en ese campo debe partir de la base de una previa regulación en la ley, a la que debe ajustarse».

En el epígrafe siguiente examinaremos si en el supuesto concreto de la Sentencia comentada existe una norma legal que sirva de cobertura a la Ordenanza y si, en caso de ausencia de dicha norma, se puede acudir a otras fórmulas o técnicas jurídicas que suplanten de algún modo la exigencia constitucional de reserva de ley formal.

\section{ANÁLISIS DE LOS MOTIVOS DEL RECURSO QUE DIO LUGAR A LA STS DICTADA EN CASACIÓN EL 29 DE MAYO DE 1998}

La Ordenanza de Policía Urbana y Gobierno de la Villa de Madrid tipifica una conducta ilícita en su artículo 32.15 al regular y sancionar el consumo en la vía pública, fuera de los lugares autorizados por las Ordenanzas y Reglamentos municipales, de cualquier clase de bebidas que contengan alcohol. Ahora bien, sabemos que el artículo 25 de la Constitución

${ }^{16}$ A. Nieto, op. cit., p. 103. 
exige, por razones de seguridad jurídica, la predeterminación a través de una norma legal de las conductas ilícitas. Asimismo, como hemos observado, esta reserva formal de ley no es absoluta sino que cabe la colaboración reglamentaria.

Lo primero que es preciso averiguar con el fin de comprobar la validez de la citada Ordenanza municipal es si ésta disfruta de cobertura legal. En este sentido, la Corporación municipal recurrente alude a los artículos 25 y 26 de la LBRL así como a la Ley Orgánica 1/1992, de 21 de febrero, sobre Protección de la Seguridad Ciudadana. Por lo que se refiere a esta última cabe apuntar que esta norma ha sido modificada por la Ley 10/1999, de 21 de abril ${ }^{17}$, con el único fin de habilitar a los municipios a especificar en sus respectivas ordenanzas los tipos, definidos en la ley, que corresponden a las infracciones cuya sanción se atribuye a los Alcaldes. Con ello se pretende, según señala la Exposición de Motivos de la citada norma, "solucionar las dificultades que viene planteando a los Alcaldes la ausencia de una habilitación expresa en la Ley para que las ordenanzas municipales puedan establecer dicha especificación dentro del tipo correspondiente a cada infracción definida en el propio texto legal». Con este fin se añade un nuevo párrafo al final del apartado 2 del artículo 29 de la Ley Orgánica 1/1992, de 21 de febrero, de Protección de la Seguridad Ciudadana. A nuestro juicio, ésta no es una novedad en la medida en que esta posibilidad de establecer mediante disposiciones reglamentarias especificaciones en el cuadro de infracciones establecidas legalmente ya estaba prevista con carácter general en el artículo 129.3 de la LPC. No obstante, la Ley de Protección de la Seguridad Ciudadana es una Ley posterior a la modificación de la Ordenanza (1989) y carece de efecto convalidante, por lo que no es necesario entrar a estudiar sus preceptos con el fin de hallar en su contenido un efecto habilitante. Descartada pues esta segunda opción, procede someter a examen la primera, es decir, determinar qué ocurre a dichos efectos habilitantes con los artículos 25 y 26 de la LBRL. El análisis de estos preceptos nos permite comprobar que el legislador ha diseñado una lista de materias y servicios que a los entes municipales les corresponderá gestionar y sobre los que serán competentes en la medida en que lo determine una ley estatal o autonómica. Esto significa que las conductas ilícitas que se pudiesen tipificar en relación con estas materias deben estar contenidas en la ley sectorial que atribuya la gestión de dicha materia al ente local. En consecuencia, no se puede entender cubierta la reserva legal exigida por el artículo 25 de la Constitución reali-

\footnotetext{
17 Ésta es una norma contenida en el paquete de medidas legislativas aprobadas bajo el nombre de «Pacto Local» que suponen la reforma de varias leyes para lograr el fortalecimiento de los entes locales en el proceso de descentralización y, dentro de ellos, del Alcalde.
} 
zando, como señala el TS, «genéricas referencias a las competencias municipales sobre determinadas materias».

El Ayuntamiento recurrente también invoca, como fundamento de la validez de la sanción impuesta y del reglamento en que se apoya, al principio de autonomía de las entidades locales y a la facultad de aprobar ordenanzas y reglamentos que la Ley les reconoce. De esta forma, se pone en conexión la potestad reglamentaria con la sancionatoria, ambas previstas en el artículo 4 letras a) y f) de la LBRL. Se trata de cuestiones íntimamente relacionadas que permiten un análisis conjunto.

En primer lugar, hemos de recordar, una vez más, que la autonomía local significa, de acuerdo con el artículo 137 de la Constitución, «autonomía para la gestión de sus respectivos intereses» ${ }^{18}$. Asimismo, sabemos que para ejercer esta autonomía los entes locales necesitan una ley sectorial, autonómica o estatal que les atribuya la competencia. Por último, no podemos olvidar que en materia sancionadora la Administración debe respetar el principio de legalidad formal enunciado en el artículo 25 de la Constitución. Todo ello implica que la ley sectorial deberá determinar los requisitos mínimos de la infracción que luego podrán desarrollar las Ordenanzas Municipales. Esto significa que hasta ese preciso momento no se pondrán en conexión la potestad sancionadora y reglamentaria constitucional y legalmente reconocidas en la Administración local. De este modo, se compatibiliza el principio de autonomía local y la reserva de ley prevista en materia sancionadora por la Constitución.

En definitva, cabe afirmar con apoyo en la doctrina más autorizada que en nuestro sistema constitucional la invocación del «principio constitucional de autonomía local carece de la menor fuerza para intentar, nada menos, que excusar a los Ayuntamientos de la necesidad de que una ley, precisamente, les habilite para actuar en este campo. El principio constitucional de autonomía local tiene, indudablemente, su importancia, el Tribunal Constitucional ha tenido ocasión de imponerlo, pero nunca nadie, que se sepa, ha pretendido cubrirse con él para intentar cubrir, nada menos, una reserva constitucional de ley»» ${ }^{19}$.

\footnotetext{
18 Entre las recientes publicaciones sobre la autonomía local puede consultarse el trabajo de J. L. Carro Fernández-VAlmayor, «El debate sobre la autonomía municipal», RAP, n. ${ }^{\circ} 147,1998$, pp. 59-95.

19 E. Garcia de EnTerria, op. cit., p. 663.
} 


\section{LA STS DE 29 DE MAYO DE 1998 Y EL REAL DECRETO 1.398/1993, DE 4 DE AGOSTO, POR EL QUE SE APRUEBA EL REGLAMENTO DE PROCEDIMIENTO PARA EL EJERCICIO DE LA POTESTAD SANCIONADORA}

Al comienzo de este trabajo justificábamos la importancia de la Sentencia del Tribunal Supremo en la que apoyamos este breve estudio sobre la potestad sancionadora de los entes locales. En este sentido, señalábamos que lo más relevante de la STS de 29 de mayo de 1998 era el momento en que fue pronunciada, esto es, en una fecha posterior a la emanación del Real Decreto 1398/1993, de 4 de agosto, por el que se aprueba el Reglamento de procedimiento para el ejercicio de la potestad sancionadora. El contenido de este Reglamento nos interesa en la medida en que algunos de sus preceptos contradicen de plano la jurisprudencia del TC y del TS.

El Reglamento alude en su artículo 1.2 a las «Ordenanzas locales que tipifiquen infracciones y sanciones» y afirma en su artículo 2.2 que «las Entidades que integran la Administración local, cuando tipifiquen como infracciones hechos y conductas mediante Ordenanzas, y tipifiquen como infracción de Ordenanzas el incumplimiento total o parcial de las obligaciones o prohibiciones establecidas en las mismas, al aplicarlas deberán respetar en todo caso las tipificaciones previstas en la Ley». Tras la lectura de estos preceptos es fácil comprobar que su tenor literal es contrario al artículo 25 de la Constitución y a los artículos 127 y 129 de la LPC. Como afirma GARCÍA DE ENTERRÍA, el contenido de este Reglamento supone una «descarada manipulación de la Constitución y las leyes» ${ }^{20}$. Quizá sea una exigencia de la realidad la necesidad, señalada por algunos autores, de someter a ciertas modulaciones el Derecho sancionador en el ámbito local ${ }^{21}$. No obstante, está claro que la vía escogida no ha sido la más adecuada teniendo en cuenta su flagrante inconstitucionalidad. En este Reglamento se ha positivizado una doctrina que previamente, aunque pa-

\footnotetext{
${ }^{20}$ E. Garcta de EnTERría, op. cit., p. 665.
}

21 Véase en este sentido, entre otros, a A. Nieto, op. cit., p. 108; J. M. TRAYTER JIMÉnEZ, op. cit., p. 46; C. NavarRo del CACHO, op. cit., p. 204; I. Sanz RubialeS, «Principio de legalidad y potestad sancionadora en la Administración Local», REALA, n. ${ }^{\circ} 264,1994$, p. 689; y J. OLIVÁN DEL CACHO, Procedimiento sancionador y Estado autonómico, Barcelona, Cedecs, 1996, p. 72.

22 En el Preámbulo de la norma se apunta que «pese a la autorizada línea doctrinal que sostiene que las ordenanzas locales, en tanto que normas dictadas por órganos representativos de la voluntad popular, son el equivalente en el ámbito local de las leyes estatales y autonómicas y tienen fuerza de 
rezca sorprendente, había sido rechazada de forma expresa en el propio Preámbulo de la norma ${ }^{22}$.

El Profesor NIETo, en su obra Derecho Administrativo Sancionador, en un intento de salvar la inconstitucionalidad de las Ordenanzas locales que tipifiquen infracciones sin que exista una previa cobertura legal, realiza una propuesta que él mismo califica de "ambiciosa». El citado autor, basándose en que el TC admite, en el ámbito de las sanciones administrativas, matizaciones de la reserva legal exigida en el Derecho penal, entiende que

«desde una perspectiva institucional ha de pensarse [...] que tanto las Ordenanzas locales como las Normas Deontológicas de un Colegio Profesional son el correlativo de las Leyes del Estado y de las Comunidades Autónomas: normas emanadas por los órganos de representación popular, a diferencia de las disposiciones del Alcalde o de la Comisión de Gobierno. En su consecuencia [...] podría admitirse que las Ordenanzas cumplen el requisito de la reserva de ley desde una perspectiva institucional y democrática. Y si esto fuera cierto, ya no habría necesidad de buscar necesariamente una cobertura en ley sectorial.

Nótese —n apoyo de esta tesis, aparentemente arriesgada - que el artículo 55 del Texto Refundido no exige que las Ordenanzas «desarrollen» o «ejecuten» una Ley previa, sino que basta con que «no se opongan a las leyes». Rige aquí, por tanto, la vieja teoría de la vinculación negativa de la Administración a la ley y no la positiva, que tan de moda está actualmente» ${ }^{23}$.

Estas manifestaciones aparecen hoy recogidas en la más reciente doctrina del Consejo de Estado, concretamente en su Dictamen de 23 de febrero de 1995, en el que el órgano consultivo recupera la doctrina de la vinculación negativa a la ley con apoyo en el artículo 55 del TR. Los argumentos en que se apoya el Consejo de Estado han sido reagrupados en tres tipos por el Profesor T.-R. FERNÁNDEZ en un trabajo en el que analiza el citado dictamen ${ }^{24}$ : i) un argumento de carácter histórico, basado en el hecho de que el ejercicio de la potestad sancionadora a través de Ordenanzas locales es tan antiguo como la existencia misma de los entes municipales; ii) un argumento de tipo práctico, apoyado en la afirmación de que la potestad sancionadora de los entes locales es inherente a la potestad de Ordenanza, de modo que negarles ese poder sería colocar a todos los Entes locales en la inconstitucionalidad; y iii) el argumento del princi-

ley en dicho ámbito, el Reglamento ha considerado necesario mantener el referente básico del principio de legalidad, de modo que las prescripciones sancionadoras de las ordenanzas completen y adapten las previsiones contenidas en las correspondientes Leyes».

${ }^{23}$ A. NiETo, op. cit., p. 109.

24 T.-R. Fernández Rodríguez, op. cit., p. 218. 
pio de autonomía y del carácter democrático de las Corporaciones Locales. En este sentido, las Ordenanzas locales, en tanto que normas dictadas por órganos representativos de la voluntad popular, son el equivalente en el ámbito local de las leyes estatales y autonómicas y tienen fuerza de ley en dicho ámbito ${ }^{25}$. El citado autor se ha ocupado de realizar un comentario detallado de todos y de cada uno de los argumentos esgrimidos por el Consejo de Estado. Con sus críticas, apoyadas en todo caso, de forma escrupulosa no sólo en la ley, sino también en los dictados de la Constitución y en la interpretación que de la misma ha realizado el TC, ha logrado demostrar que la nueva tesis ${ }^{26}$ del Consejo de Estado y los principios que la sustentan no son lo suficientemente sólidos para mantenerse en pie ${ }^{27}$.

El criterio de la vinculación negativa de la Administración a la ley con apoyo en el artículo 55 del TR es sencillamente «baladí» ${ }^{28}$. Entendemos que el legislador en este precepto hace referencia, de manera poco afortunada -como señalan GoNZÁlEZ PÉREZ y GONZÁLEZ NAVARRO-, al hecho de que las Ordenanzas locales deben respetar el principio de jerarquía normativa ${ }^{29}$. No hay que olvidar que la actividad sancionadora de la Administración es una actividad administrativa y la doctrina de la vinculación positiva de la Administración a la ley opera también en este ámbito ${ }^{30}$. Por lo tanto, es necesaria una habilitación legal específica que en el caso de la Administración municipal debe buscarse en la legislación sectorial.

A nuestro juicio, el más importante de los argumentos esgrimidos por T.-R. FERNÁNDEZ es la cuestión —crucial e indiscutible - de que estamos ante una materia, la sancionadora, que incide de forma directa en la libertad de los ciudadanos y, en este sentido, la ley es, como manifiesta el citado Profesor, la salvaguardia y la protección de la libertad de todos y

\footnotetext{
${ }^{25}$ En nuestra doctrina, la tesis de la naturaleza legisladora de los entes locales ha sido puesta de manifiesto y defendida por L. PAREJO ALFONSO en su libro Administrar y juzgar: dos funciones constitucionales distintas y complementarias, Madrid, Tecnos, 1993, pp. 79 y ss.
}

${ }^{26}$ La postura defendida por el Consejo de Estado en sus primeros pronunciamientos sobre esta cuestión, esto es, en su Dictamen de 15 de octubre de 1982, fue exactamente la contraria a la defendida en el Dictamen ahora comentado.

${ }^{27}$ Sus argumentaciones pueden consultarse en la obra citada, pp. 221 y ss.

${ }^{28}$ T.-R. Fernández RodŔGUeZ, op. cit., p. 222.

29 J. González Perez y F. González Navarro, op. cit., p. 1866.

${ }^{30}$ E. GaRCí Llovet, «La normalización constitucional del poder punitivo de la Administración. Potestad sancionadora y procedimiento sancionador en la Ley 30/1992», Revista Xuridica Galega, n. ${ }^{\circ} 4,1993$, p. 57. 
de cada uno, la garantía de esa libertad que todos sostenemos porque es igual para todos $\mathrm{y}$, por lo tanto, asegura también en la misma medida nuestra propia libertad individual.

Esta cuestión se encuentra en estrecha conexión con el principio de igualdad asimismo positivizado en el Texto Constitucional. En esta línea argumental, cabe recordar el tenor literal de su artículo 139.1, que dispone que «todos los españoles tienen los mismos derechos y obligaciones en cualquier parte del territorio del Estado». Este principio se vería vulnerado, como afirma GARCíA DE ENTERRÍA, si «todos los Ayuntamientos y Diputaciones del país, Comarcas, las Mancomunidades y hasta las Entidades Locales menores, van a creer que pueden tipificar libremente infracciones, incluso de manera vaga e incierta, así como fijar sanciones en la materia de su competencia, del mismo modo que dictar los más imaginativos procedimientos para imponer esas sanciones») ${ }^{31}$.

De todos modos, la mayoría de la doctrina coincide en la necesidad de encontrar una solución a la peculiar situación en la que se encuentran los entes locales en relación con el Derecho sancionador. Así, algún autor, como TRAYTER JIMÉNEZ, defiende la posibilidad de tipificar a través de ordenanzas locales «ciertas acciones relacionadas con la convivencia ciudadana», siempre y cuando que «su sanción no excediera de los límites previstos en el artículo 5 del TRRL». El autor apoya su tesis en la teoría de la diferenciación cuantitativa entre el Derecho penal y el Derecho administrativo sancionador. En relación con esta teoría nos encontramos con un primer problema derivado de la necesidad de delimitar el concepto "convivencia ciudadana», es decir, precisar qué cabe dentro de dicho concepto y qué es lo que queda fuera. A nuestro juicio, el único criterio objetivo que la Administración podría utilizar es el de la cuantía de la sanción a imponer. De esta forma, para determinar si estamos ante una actuación que perturba o no la convivencia ciudadana, el ente local tendría primero que decidir la cuantía de la sanción que le corresponde y, en función de ello, acordar si se trata o no de una actuación que afecta a las normas elementales de la convivencia diaria de los ciudadanos. Es fácil comprobar que esto supondría una alteración del orden normal de las cosas en el ámbito de la potestad sancionadora de los entes locales.

Por otra parte, sería dificil justificar por qué se establece como límite para el ejercicio de la potestad sancionadora por parte de los entes locales el de la tipificación de infracciones cuya sanción no exceda de la cuantía

31 E. García de EnTERría, op. cit., p. 672. 
prevista en el artículo 59 del TR, y en cambio por qué no se puede utilizar con el mismo fin, esto es, la tipificación de infracciones por las Ordenanzas locales, el referente de las sanciones previstas en otros textos legales.

Por todo ello, nos parece que la solución más acertada es la de aquel sector doctrinal que se inclina por la creación de una ley ad hoc. Esto es, «una ley especial sobre materia sancionatoria local, al menos en la parte no cubierta por las leyes sectoriales hoy existentes» ${ }^{32}$. Con la aprobación de una ley de este carácter se lograría que las Ordenanzas locales tipificadoras de infracciones, dictadas con posterioridad a la citada ley, no adolezcan de inconstitucionalidad al respetar el principio de legalidad sancionado en el artículo 25 del Texto Constitucional.

32 E. GarCIA DE ENTERRIA, op. cit., p. 672. 


\section{Reseñas de legislación y jurisprudencia}


